\title{
Surface Modification of Aluminized Cu-10Fe Alloy by High Current Pulsed Electron Beam
}

\author{
Zhiming Zhou ${ }^{a}$, Baofeng Chen ${ }^{a}$, Linjiang Chai ${ }^{a *}$, Yaping Wang ${ }^{b}$, Weijiu Huang ${ }^{a}$, Minmin Cao ${ }^{a}$, \\ Bingwei Wei $^{a}$ \\ ${ }^{a}$ College of Materials Science and Engineering, Chongqing University of Technology, Chongqing, \\ China \\ ${ }^{b}$ School of Science, Xi'an Jiaotong University, Xi'an, China
}

Received: April 22, 2016; Revised: August 18, 2016; Accepted: September 7, 2016

\begin{abstract}
$\mathrm{ACu}-10 \mathrm{Fe}$ alloy with magnetron sputtered $\mathrm{Al}$ films was irradiated by high current pulsed electron beam (HCPEB) with various pulse numbers, next changes of its microstructure and corrosion property were investigated. Compared with the initial sample, microhardness and corrosion resistance of the aluminized $\mathrm{Cu}-10 \mathrm{Fe}$ alloys after the HCPEB treatment are remarkably improved with increasing pulse numbers. This improvement could be attributed to formation of $\mathrm{Al}_{2} \mathrm{Cu}$ intermetallic compounds, occurrence of liquid phase separation and grain refinement in the surface layer of the $\mathrm{Cu}-10 \mathrm{Fe}$ alloy during the process of rapid remelting and solidification induced by the HCPEB treatment.
\end{abstract}

Keywords: $\mathrm{Cu}$-10Fe alloy, surface modification, $H C P E B$, liquid phase separation, corrosion resistance

\section{Introduction}

In recent years, high current pulsed electron beam (HCPEB) has emerged as a new and promising surface modification technique for materials researchers. Compared to widely used laser, plasma, and ion beam treatments, the HCPEB provides narrower energy distribution, better surface finish and wider energy density range ${ }^{1-4}$. With proper selection of operation parameters, various surface modification processes like surface quenching, annealing, impulse hardening, alloying and amorphization can be achieved by HCPEB treatments ${ }^{5,6}$. As a result, optimized mechanical strength, microhardness, wear and corrosion resistance may be obtained. To date, there have been many successful applications of the HCPEB technique to enhancing surface performance of steels ${ }^{7,8}$, magnesium alloys ${ }^{8,9}$, aluminum alloys ${ }^{10,11}$, etc.

Thanks to excellent electrical properties and reliable performance, $\mathrm{Cu}$-Fe alloys account for approximately half of contact materials for vacuum interrupters ${ }^{12}$. Cu-Fe alloys utilize $\mathrm{Cu}$ as the matrix element with $\mathrm{Fe}$ and other trace elements added to form different grades of alloys. By and large, they belong to metastable immiscible alloys, with good application prospects in aviation, automobile and electronic industries. Along with the rapid development of long-pulsed magnetic field and high-speed railway technologies, higher requirements for magnetic conductors and electrical contact materials have been asked ${ }^{13,14}$. For the $\mathrm{Cu}$-Fe contact materials, better strength, electrical conductivity, wear resistance and corrosion resistance properties should be of primary consideration ${ }^{15}$. There are already some attempts ${ }^{16,17}$ on preparation techniques for producing stronger, more ductile and higher conductive

\footnotetext{
* e-mail: chailinjiang@cqut.edu.cn
}

$\mathrm{Cu}-\mathrm{Fe}$ alloys. However, few attentions have been paid to the effect of the HCPEB technique on the surface modification of $\mathrm{Cu}-\mathrm{Fe}$ alloys, in spite of its well testified effectiveness for other metallic materials ${ }^{18-20}$. In this paper, the modification effects of the HCPEB treatment on the surface of $\mathrm{Cu}-10 \mathrm{Fe}$ alloys coated with Al films were studied. The reason for depositing $\mathrm{Al}$ films on the surface of $\mathrm{Cu}-10 \mathrm{Fe}$ alloys is that $\mathrm{Al}, \mathrm{Cu}$ and $\mathrm{Fe}$ are easy to generate complex intermetallics and could improve corrosion and wear resistance. Surface microhardness and corrosion resistance properties of samples with and without the HCPEB treatment were measured, and reasons accounting for their changes were discussed in light of microstructural characterization.

\section{Experimental}

The substrate $\mathrm{Cu}-10 \mathrm{Fe}$ alloy was prepared by vacuum induction melting (VIM). Specimens with dimensions of $\Phi 14 \mathrm{~mm} \times 3 \mathrm{~mm}$ were cut from the as-prepared $\mathrm{Cu}-10 \mathrm{Fe}$ alloy. All the samples were ground and polished, followed by ultrasonic cleaning in alcohol for 5 minutes. A FJL560A type ultrahigh vacuum magnetron and ion beam sputtering system was employed to deposit Al films on the surface of $\mathrm{Cu}-10 \mathrm{Fe}$ alloys. Technology principle and advantage of the plasma-enhanced magnetic sputtering could be found elsewhere ${ }^{21}$. Prior to the deposition, the system was evacuated to a vacuum pressure about $10 \mathrm{~Pa}$ by a mechanical pump. Then a molecular pump was used to reach a high vacuum of about $3.4 \times 10^{-4} \mathrm{~Pa}$ for the system to avoid contamination and improve adhesion. During the deposition, the working pressure was maintained at $0.9 \sim 1 \mathrm{~Pa}$, the target power was $125 \mathrm{~W}$, and sputtering time was 20 minutes. A RT-2M type 
HCPEB source was then employed to irradiate the surface of $\mathrm{Cu}-10 \mathrm{Fe}$ alloys at room temperature, with pulse numbers of $1,5,15$ and 30 , respectively. The HCPEB treatments were conducted under the following conditions: the electron energy $25 \mathrm{keV}$, the pulse duration $1 \mu \mathrm{s}$, the spray distance $80 \mathrm{~mm}$, and the vacuum $5 \times 10^{-3} \mathrm{~Pa}$. More details about the HCPEB system can be found in Refs. ${ }^{22,23}$.

Microstructures of the samples were characterized by an Olympus GX51 optical microscope (OM) and a JEOL JSM-6460LV scanning electron microscope (SEM) equipped with an energy dispersive spectrometer (EDS). Cross-section microhardness of the samples was measured by a HVS-1000 testing instrument. Phase changes in the surface layers were examined by a DX-2700 X-ray diffractometer (XRD) with $\mathrm{CuK}_{\alpha}$ radiation. Meanwhile, the corrosion resistance was measured by using a M273 electrochemical workstation. With respect to corrosion process, 3.5wt.\% $\mathrm{NaCl}$ solution was selected as the corrosive medium. The corrosion current density was estimated by Tafel extrapolation of the polarization curve.

\section{Results}

\subsection{Surface and cross-section morphologies}

Microstructure of the substrate $\mathrm{Cu}-10 \mathrm{Fe}$ alloy as-prepared by the VIM is illustrated in Figure 1. As clearly shown in Figure 1a, coarse dendrites of primary Fe-rich phases are dispersed in the $\mathrm{Cu}$ matrix. Figure $1 \mathrm{~b}$ shows the cross-section OM micrograph of $\mathrm{Cu}-10 \mathrm{Fe}$ alloy with deposited $\mathrm{Al}$ films. From the cross-sectional image, one can see that the Al film with columnar morphology has a thickness of about $6 \mu \mathrm{m}$. A very low adhesive strength of Al film on the substrate material is expected.

The SEM micrographs of the microstructure of aluminized $\mathrm{Cu}-10 \mathrm{Fe}$ alloys irradiated by the HCPEB with different pulses are displayed in Figure 2. As shown in Figure 2a, a few craters with different sizes are formed on the surface of Al films after a single shot. Cross-section composition analyses by the SEM-EDS reveal that Al element is almost exclusively detected on the surface of one-pulse treated sample, suggesting that only an insignificantly remelted layer is produced (Figure $2 \mathrm{~b}$ ). As the pulse number increases to 5 (Figure 2c), most of the $\mathrm{Al}$ films are remelted and remarkable element aggregation is found. Meanwhile, in addition to craters, cracks also appear as revealed by the magnified images in Figs. 2d and 2e. After the 15-pulse treatment (Figure 2f), more craters are observed on the irradiated surface, similar to other metallic materials after HCPEB treatments ${ }^{24,25}$. When the pulse number reaches 30 (as shown in Figure 2g), the Al films sputtered on the surface of the $\mathrm{Cu}-10 \mathrm{Fe}$ alloy almost disappear. Instead, a clearly remelted layer with a thickness of about $10 \mu \mathrm{m}$ is observed (Figure 2h). EDS analyses across the remelted layer reveal that both $\mathrm{Fe}$ and $\mathrm{Cu}$ elements are present in the surface layer, in addition to $\mathrm{Al}$ element. Furthermore, composition changes are also found for prior Fe-rich phases and the $\mathrm{Cu}$ matrix. Extra EDS analyses reveal 7.35 wt.\% Al in Fe-rich phases and $74.3 \mathrm{wt} . \% \mathrm{Al}$ and $25.7 \mathrm{wt} . \% \mathrm{Cu}$ for intermetallics formed in $\mathrm{Cu}$ matrix, confirming the occurrence of remarkable alloying on the surface.

\subsection{XRD analysis}

XRD measurements were carried out for the aluminized $\mathrm{Cu}-10 \mathrm{Fe}$ alloys before and after HCPEB treatments and results are shown in Figure 3. One can notice that $\mathrm{Cu}$ and $\alpha-F e$ phases are always the majority in the surface layers of all samples. Nevertheless, a new phase of $\mathrm{Al}_{2} \mathrm{Cu}$ is definitely detected in those HCPEB-treated samples. This is consistent with the microstructural analysis according to Figure 2.
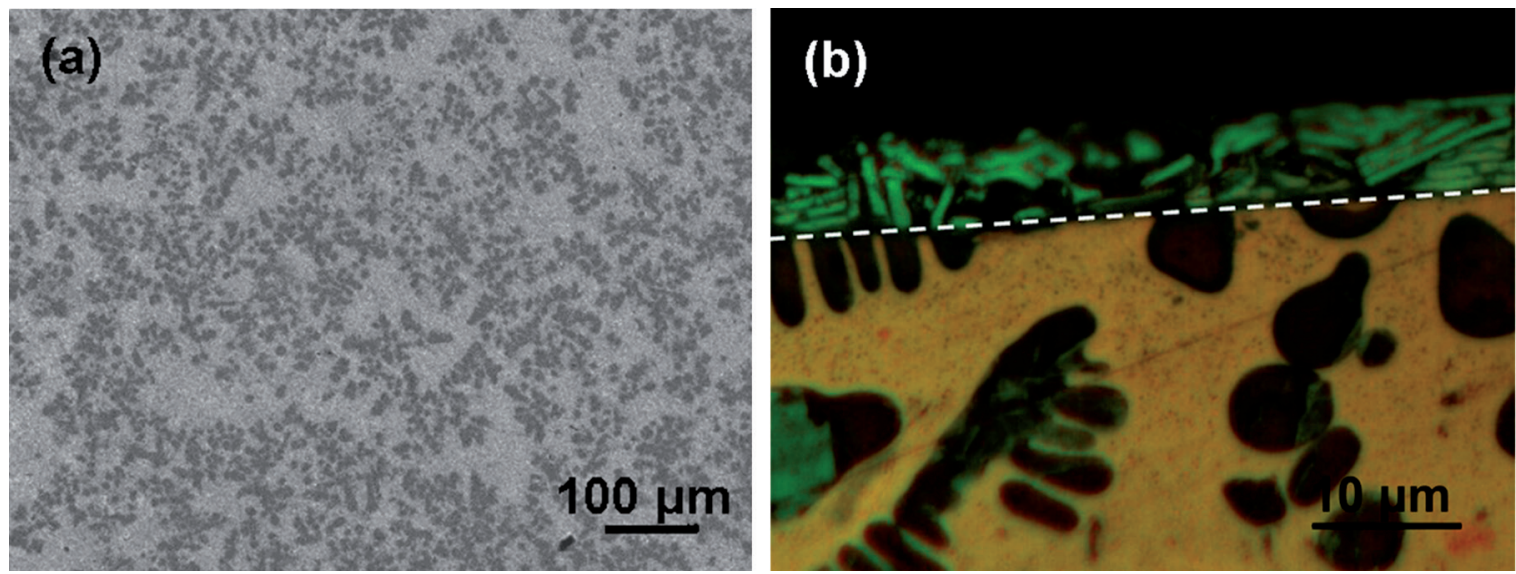

Figure 1: (a) surface SEM micrograph of the $\mathrm{Cu}-10 \mathrm{Fe}$ master alloy (the gray and the light indicate Fe-rich phases and $\mathrm{Cu}$-rich substrate, respectively); (b) cross-section optical micrograph of $\mathrm{Cu}-10 \mathrm{Fe}$ alloy coated with $\mathrm{Al}$ films (the white dashed line roughly indicates the interface between $\mathrm{Al}$ films and substrate) 

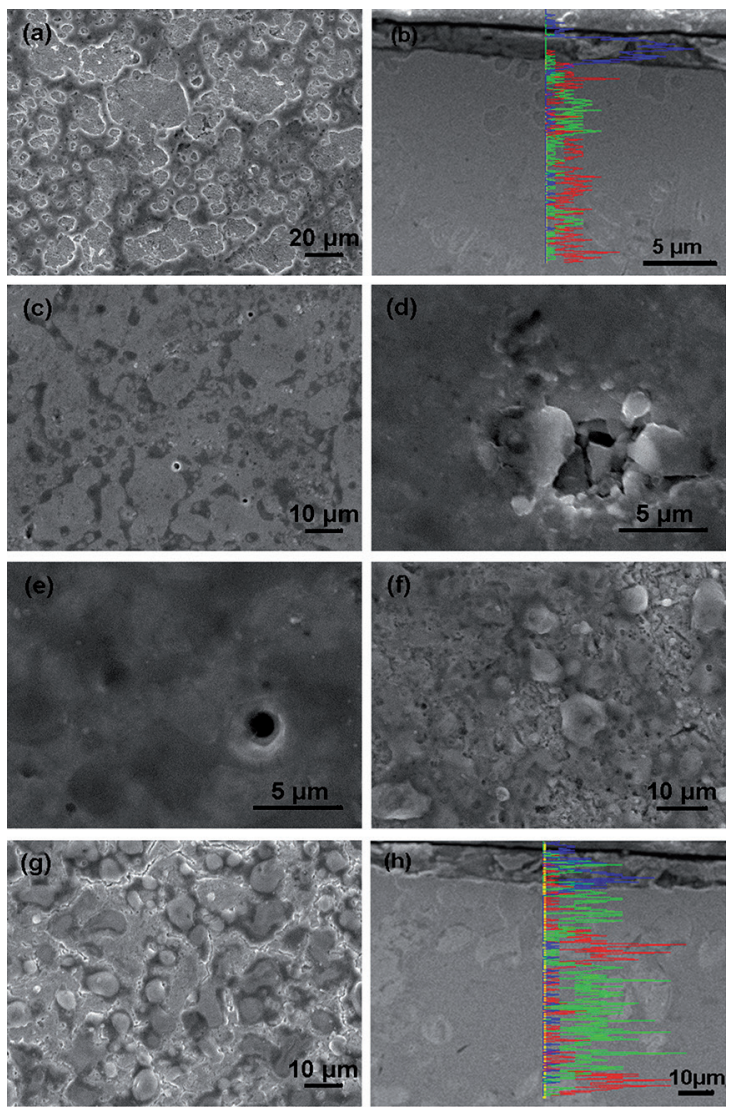

Figure 2: Micrographs and EDS results (red, green and blue lines indicate $\mathrm{Cu}, \mathrm{Fe}$ and $\mathrm{Al}$, respectively) illustrating microstructures of $\mathrm{Cu}-10 \mathrm{Fe}$ alloys with different pulses: (a) and (b) 1 pulse; (c), (d) and (e) 5 pulses; (f) 15 pulses; (g) and (h) 30 pulses

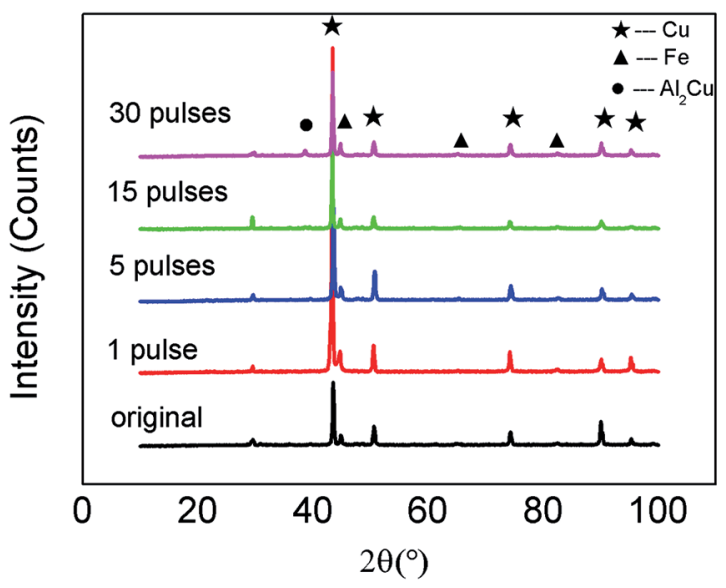

Figure 3: $\mathrm{XRD}$ patterns of the aluminized $\mathrm{Cu}-10 \mathrm{Fe}$ alloys with and without HCPEB irradiation

\subsection{Microhardness and coefficient of friction}

Microhardness variation from surface layers to substrates and coefficients of friction (COFs) all samples are measured and presented in Figure 4. From Figure 4a, one can see that for the unirradiated sample, the top surface appears to be the softest, followed by an almost constant hardness value towards the substrate. This is because that the top surface is composed of relatively soft $\mathrm{Al}$ films, compared with the harder substrate. After HCPEB treatments, however, significant hardness increase can be noticed for the top surface of samples; the prior softest part becomes the hardest even for the sample with a single shot. With increasing pulse numbers, a general increase trend is seen for the top surfaces of the irradiated samples. For the 30-pulse treated sample, highest hardness value $(256 \mathrm{HV})$ is obtained in the current work, which is $45 \%$ higher than the as-sputtered $\mathrm{Al}$ film.

Figure $4 \mathrm{~b}$ presents the surface COFs measured for all samples. For the unirradiated sample, the COF is about 0.5 . After one-pulse treatment, the COF rapidly increases to higher than 0.6. As the pulse number increases, a clear decrease trend can be seen, with the lowest COFs value of about 0.3 achieved for the 30 -pulse treated sample.

\subsection{Corrosion resistance}

The polarization curves and corrosion current densities are displayed in Figure 5 and Table 1 to reveal the change of corrosion resistance between the initial and irradiated samples. According to the Tafel extrapolation, corrosion current density $\left(\mathrm{I}_{\text {corr }}\right)$, corrosion potential $\left(\mathrm{E}_{\text {corr }}\right)$ and corrosion rate are acquired and given in Table 1. From both Figure 5 and Table 1, one can see after the HCPEB irradiation, $\mathrm{E}_{\text {corr }}$ and $\mathrm{I}_{\text {corr }}$ of all samples with various pulse numbers are respectively higher and lower than the unirradiated sample. For the most heavily irradiated sample (30 pulses), the highest $\mathrm{E}_{\text {corr }}$ and the lowest $\mathrm{I}_{\text {corr }}$ are obtained. Generally, a lower corrosion current density indicates a slower corrosion rate. This is also the case in the present work, as revealed in Table 1. Therefore, the corrosion resistance can be effectively improved by the HCPEB treatment. The sample irradiated for 30 pulses presents the best corrosion resistance, corrosion rate of which is 6 times slower than the initial sample.

\section{Discussion}

Due to the high accelerating voltage $(25 \mathrm{keV})$ and high energy density of the HCPEB treatments employed in this work, the surface of $\mathrm{Cu}-10 \mathrm{Fe}$ alloys with $\mathrm{Al}$ films could be remelted rapidly and produce splashing phenomenon. Even for sample with only one pulse, craters with various sizes are formed as shown in Figure 2a. With further irradiation, as seen from the surface morphology after 5-pulse irradiation (Figure 2c), a great mass of $\mathrm{Al}$ films melt with craters and cracks appearing (Figs. 2d and 2e). As the pulse number increases, the phenomenon of remelting and rapid solidification would continue near the surface of the $\mathrm{Cu}-10 \mathrm{Fe}$ alloy. According to binary $\mathrm{Cu}-\mathrm{Fe}$ phase diagram, metastable liquid phase separation could appear during the process of rapid solidification. The occurrence of surface alloying and cracks is more evident 

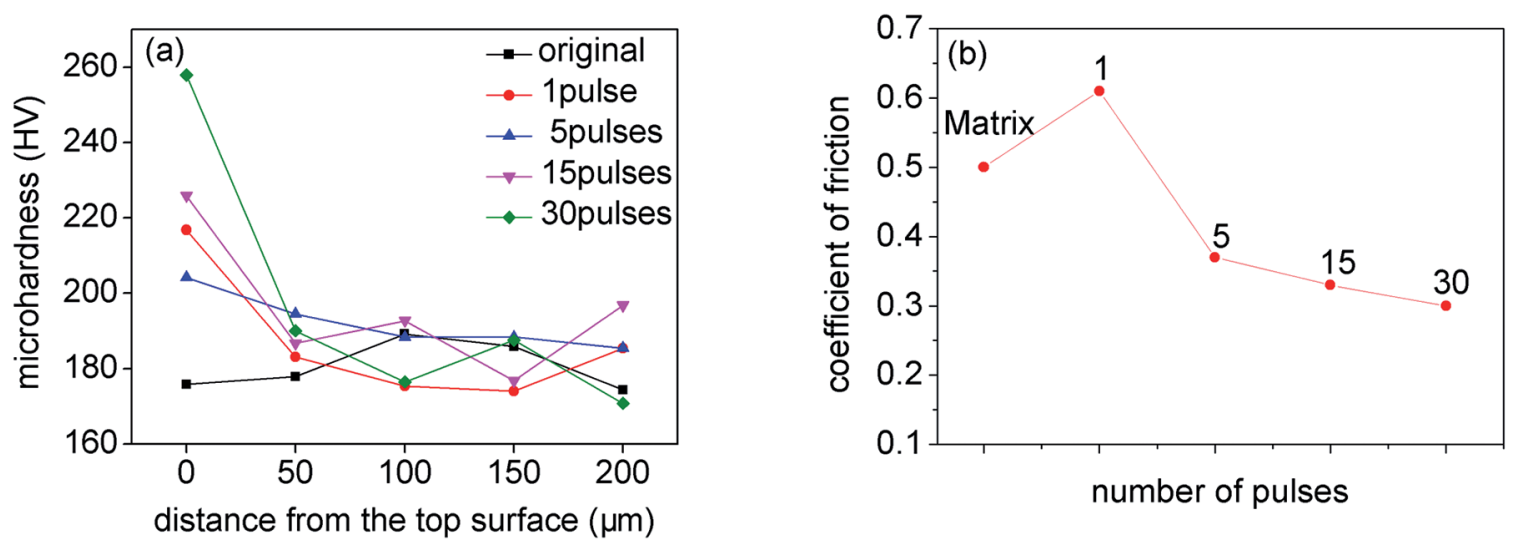

Figure 4: (a) Microhardness and (b) coefficient of friction of the aluminized $\mathrm{Cu}-10 \mathrm{Fe}$ alloys with and without HCPEB irradiation
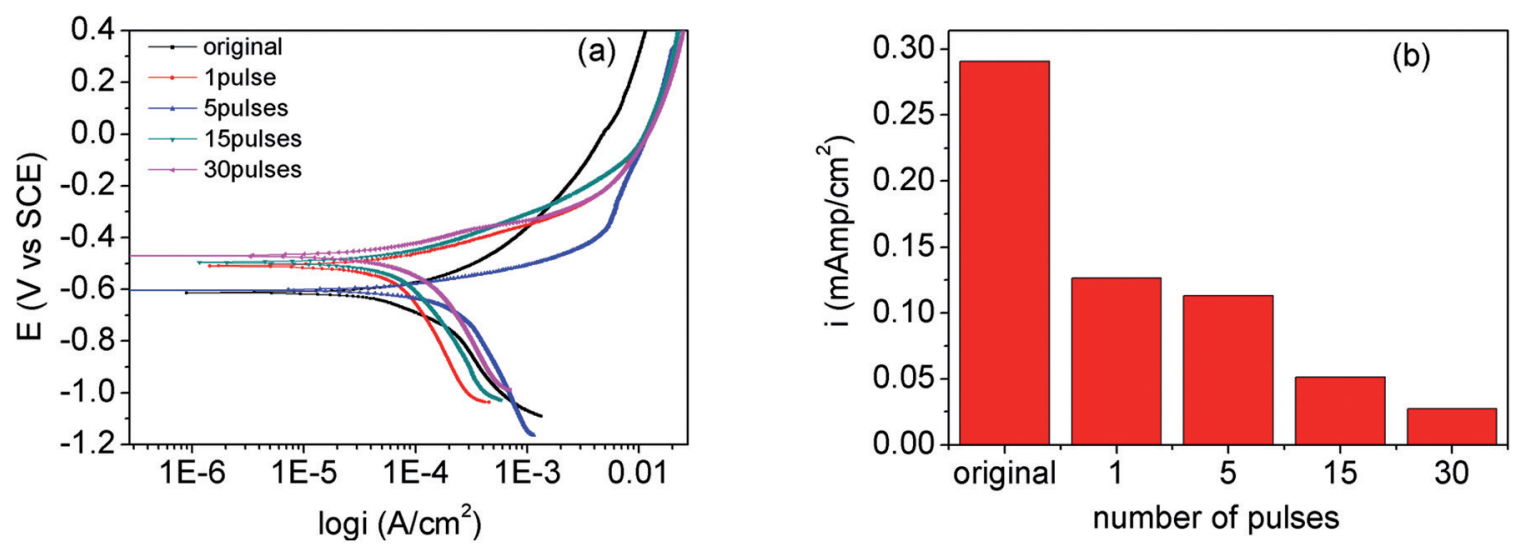

Figure 5: (a) polarization curves and (b) corrosion current density of the aluminized $\mathrm{Cu}-10 \mathrm{Fe}$ alloys with and without HCPEB irradiation

Table 1: Corrosion data of the aluminized $\mathrm{Cu}-10 \mathrm{Fe}$ alloys with and without HCPEB irradiation.

\begin{tabular}{lccc}
\hline sample & $\mathrm{E}_{\text {corr }} / \mathrm{mV}$ & $\mathrm{I}_{\text {corr }} /\left(\mu \mathrm{A} / \mathrm{cm}^{2}\right)$ & Corrosion Rate $(\mathrm{mm} / \mathrm{a})$ \\
\hline initial & -613.1 & 290.75 & 8.60 \\
1 pulse & -452.5 & 126.58 & 6.52 \\
5 pulses & -602.9 & 113.13 & 5.83 \\
15 pulses & -475.4 & 51.22 & 2.64 \\
30 pulses & -419.0 & 27.23 & 1.43 \\
\hline
\end{tabular}

when the pulse number increases to 30 (Figure 2g). From EDS and XRD analyses, the new $\mathrm{Al}_{2} \mathrm{Cu}$ phases are formed on the alloy surface. The formation of the $\mathrm{Al}_{2} \mathrm{Cu}$ intermetallic compounds is believed to relate to large differences of atomic radii and electro-negativity between $\mathrm{Cu}$ and $\mathrm{Al}$. $\mathrm{As}$ the $\mathrm{Al}_{2} \mathrm{Cu}$ compound owns high melting point and hardness, they can make major contribution to improve the surface strength, hardness, wear resistance and heat resistance.

The cross-section microhardness profile presents a downtrend from the top surface to the alloy substrate (Figure 4(a)), primarily due to considerable energy loss in the process of high energy particle effect gradually diffused to the substrate by HCPEB irradiation ${ }^{26}$. The force is gradually decreased from the surface to the substrate in the heat-affected zone formed in the range of $200 \mu \mathrm{m}$.
A slight COF increase of the alloy surface after one-pulse irradiation (Figure 4(b)) may be attributed to the formation of coarse craters. Subsequently, it decreases rapidly with increasing pulse number. Actually, the final hardness of specimens is affected mainly by the following two factors: the surface alloying which leads to the formation of the $\mathrm{Al}_{2} \mathrm{Cu}$ phase and the fine grain structure induced by the rapid solidification of the melted layer. The formation of Fe-rich spheres due to liquid phase separation during the process of HCPEB treatments is another reason for the increased surface microhardness.

The improvement of corrosion resistance can be attributed in part to the generation of $\mathrm{Cu}_{2} \mathrm{O}$ by oxidation-reduction reaction in $3.5 \mathrm{wt} . \% \mathrm{NaCl}$ solution $^{27}$. The occurrence of remelting and rapid solidification of the surface layer can 
greatly improve its microstructure refinement and inhibit localized corrosion. Meanwhile, rapid solidification increases the solubility of alloys, dissolving the elements into the matrix. This reduces the generation of harmful precipitates and leads to better corrosion resistance. Generation of supersaturated solid solution after metastable liquid phase separation may be another reason for improved corrosion resistance. In addition, the liquid phase separation-induced fine spheroids were reported ${ }^{28}$ to be able to disrupt continuity of passive films during corrosion, thus should also contribute to improved corrosion resistance in HCPEB-treated specimens.

\section{Conclusions}

Surface microstructure and corrosion resistance of an aluminized $\mathrm{Cu}-10 \mathrm{Fe}$ alloy after HCPEB treatments were investigated. Results show that typical craters could be induced by HCPEB treatments in $\mathrm{Cu}-10 \mathrm{Fe}$ alloy. The microstructure, microhardness, coefficient of friction and phase constitution could be remarkably modified by the HCPEB treatments. The surface microhardness can be increased by more than $45 \%$, due to combined effects of the fine grain structure induced by the rapid solidification of the melted layer, the occurrence of $\mathrm{Al}_{2} \mathrm{Cu}$ phase and liquid phase separation. These factors also significantly improve the corrosion resistance of $\mathrm{Cu}-10 \mathrm{Fe}$ alloy, with the best corrosion resistance obtained in the 30-pulsed sample.

\section{Acknowledgments}

This study is financially supported by the National Natural Science Foundation of China (51101177, 51401040, 51401039, 51171146 and 51171216) and the Natural Science Foundation of Chongqing (CSTC2015ZDCY-ZTZX0201, CSTC2012JJA245 and CSTC2013JCYJA50016). China Postdoctoral Science Foundation (2015M572446), Postdoctoral Science Foundation of Chongqing (Xm2015003), and Scientific and Technological Research Program of Chongqing Municipal Education Commission (KJ1500901).

\section{References}

1. Mei XX, Fu JQ, Li XN, Sun WF, Dong C, Wang YN. Surface nanostructure of a directionally solidified Ni-based superalloy DZ4 induced by high intensity pulsed ion beam irradiation. Applied Surface Science. 2012;258(20):8061-8064.

2. Zou J, Zhang K, Grosdidier T, Dong C. Analysis of the evaporation and re-condensation processes induced by pulsed beam treatments. International Journal of Heat and Mass Transfer. 2013;64:1172-1182.

3. Mei XX, Liu X, Wang C, Wang Y, Dong C. Improving oxidation resistance and thermal insulation of thermal barrier coatings by intense pulsed electron beam irradiation. Applied Surface Science. 2012;263:810-815.
4. Proskurovsky DI, Rotshtein VP, Ozur GE, Ivanov YF, Markov AB. Physical foundations for surface treatment of materials with low energy, high current electron beams. Surface and Coatings Technology. 2000;125(1):49-56.

5. Zou JX, Zhang KM, Grosdidier T, Dong C, Qin Y, Hao SZ, et al. Orientation-dependent deformation on $316 \mathrm{~L}$ stainless steel induced by high-current pulsed electron beam irradiation. Materials Science and Engineering: A. 2008;483-484:302-305.

6. Zhang KM, Zou JX, Bolle B, Grosdidier T. Evolution of residual stress states in surface layers of an AISI D2 steel treated by low energy high current pulsed electron beam. Vacuum. 2013;87:60-68.

7. Samih Y, Marcos G, Stein N, Allain N, Fleury E, Dong C, et al. Microstructure modifications and associated hardness and corrosion improvements in the AISI 420 martensitic stainless steel treated by high current pulsed electron beam (HCPEB). Surface and Coatings Technology. 2014;259(Pt C):737-745.

8. Hao S, Gao B, Wu A, Zou J, Qin Y, Dong C, et al. Surface modification of steels and magnesium alloy by high current pulsed electron beam. Nuclear Instruments and Methods in Physics Research Section B: Beam Interactions with Materials and Atoms. 2005;240(3):646-652.

9. Gao B, Hao S, Zou J, Wu W, Tu G, Dong C. Effect of high current pulsed electron beam treatment on surface microstructure and wear and corrosion resistance of an AZ91HP magnesium alloy. Surface and Coatings Technology. 2007;201(14):6297-6303.

10. Hao Y, Gao B, Tu GF, Li SW, Hao SZ, Dong C. Surface modification of Al-20Si alloy by high current pulsed electron beam. Applied Surface Science. 2011;257(9):3913-3919.

11. Hao Y, Gao B, Tu GF, Cao H, Hao SZ, Dong C. Surface modification of Al-12.6Si alloy by high current pulsed electron beam. Applied Surface Science. 2012;258(6):2052-2056.

12. He J, Zhao JZ, Ratke L. Solidification microstructure and dynamics of metastable phase transformation in undercooled liquid $\mathrm{Cu}-\mathrm{Fe}$ alloys. Acta Materialia. 2006;54(7):1749-1757.

13. Dai J, Yin Z, Zhang J. Effects of thermomechanical treatment on microstructure and properties of $\mathrm{Cu}-0.1 \mathrm{wt} \% \mathrm{Fe}-0.03 \mathrm{wt} \% \mathrm{P}$ alloy. Heat Treatment of Metals. 2008;33(2):64-68.

14. Zhang Y, Gao J, Yasuda H, Kolbe M, Wilde G. Particle size distribution and composition in phase-separated $\mathrm{Cu}_{75} \mathrm{Co}_{25}$ alloys under various magnetic fields. Scripta Materialia. 2014;82:5-8.

15. Zhang Y, Simon C, Volkmann T, Kolbe M, Herlach D, Wilde G. Nucleation transitions in undercooled $\mathrm{Cu}_{70} \mathrm{Co}_{30}$ immiscible alloy. Applied Physics Letters. 2014;105(4):041908.

16. Hong SI, Song JS, Kim HS. Thermo-mechanical processing and properties of $\mathrm{Cu}-9 \mathrm{Fe}-1.2 \mathrm{Co}$ microcomposite wires. Scripta Materialia. 2001;45(11):1295-1300.

17. Maggio RD, Ischia G, Bortolotti GM, Rossi F, Molinari A. The microstructure and mechanical properties of $\mathrm{Fe}-\mathrm{Cu}$ materials fabricated by pressure-less-shaping of nanocrystalline powders. Journal of Materials Science. 2007;42(22):9284-9292.

18. Chai LJ, Zhou ZM, Xiao ZP, Tu J, Wang YP, Huang WJ. Evolution of surface microstructure of $\mathrm{Cu}-50 \mathrm{Cr}$ alloy treated by high current pulsed electron beam. Science China Technological Sciences. 2015;58(3):462-469. 
19. Gao Y. Surface modification of TC4 titanium alloy by high current pulsed electron beam (HCPEB) with different pulsed energy densities. Journal of Alloys and Compounds. 2013;572:180-185.

20. Cai J, Yang SZ, Ji L, Guan QL, Wang ZP, Han ZY. Surface microstructure and high temperature oxidation resistance of thermal sprayed CoCrAlY coating irradiated by high current pulsed electron beam. Surface and Coatings Technology. 2014;251:217-225.

21. Wang Y, Li Z, Du J, Wang B. Mechanical properties of the plasma-enhanced magnetron sputtering $\mathrm{Si}-\mathrm{C}-\mathrm{N}$ coatings. Applied Surface Science. 2010;257(1):1-5.

22. Dong C, Wu A, Hao S, Zou J, Liu Z, Zhong P, et al. Surface treatment by high current pulsed electron beam. Surface and Coatings Technology. 2003;163:620-624.

23. Rotshtein VP, Ivanov YF, Proskurovsky DI, Karlik KV, Shulepov IA, Markov AB. Microstructure of the near-surface layers of austenitic stainless steels irradiated with a low-energy, highcurrent electron beam. Surface and Coatings Technology. 2004;180:382-386.
24. Hao S, Zhang XD, Mei X, Grosdidier T, Dong C. Surface treatment of DZ4 directionally solidified nickel-based superalloy by high current pulsed electron beam. Materials Letters. 2008;62(3):414-417.

25. Ivanov Y, Matz W, Rotshtein V, Günzel R, Shevchenko N. Pulsed electron-beam melting of high-speed steel: structural phase transformations and wear resistance. Surface and Coatings Technology. 2002;150(2-3):188-198.

26. Hao SZ, Wu PS, Zhang XD, Zou JX, Qin Y, Dong C. Surface modification by high current pulsed electron beam. Heat Treatment of Metals. 2008;33(1):77-81.

27. El-Egamy SS. Corrosion and corrosion inhibition of $\mathrm{Cu}-20 \% \mathrm{Fe}$ alloy in sodium chloride solution. Corrosion Science. 2008;50(4):928-937.

28. Yue TM, Hu QW, Mei Z, Man HC. Laser cladding of stainless steel on magnesium ZK60/SiC composite. Materials Letters. 2001;47(3):165-170. 